Baker, H., Sobotka, H. \& Hutner, S. H. (1953). J. gen. Microbiol. 9, 485-493.

\title{
Growth Requirements of some Thermophilic and Mesophilic Bacilli
}

\author{
BY H. BAKER AND H. SOBOTKA \\ Department of Chemistry, The Mount Sinai Hospital, New York 29, N.Y., U.S.A. \\ AND S. H. HUTNER \\ Haskins Laboratories, New York 17, N.Y., U.S.A.
}

SUMMARY: To approach reproducibility of mass cultures as sources of enzymes, the growth requirements of two mesophils belonging to Bacillus licheniformis and $B$. circulans, and three thermophils belonging to $B$. licheniformis, $B$. circulans and $B$. stearothermophilus, were determined in metal-buffered media.

The mesophilic B. licheniformis required glycerol or glucose, also alanine, aspartate, glycine, glutamate, arginine, histidine and lysine. Cytidylic acid or guanylic acid further increased growth; adenosine was inactive. The thermophilic $B$. licheniformis required for good growth either glycerol, gluconate, or glucose, also succinate or glutamate; glutamate was replaceable by the combination of arginine + histidine + proline. In glycerol media, either DL-malate alone, or citrate plus either acetate or fumarate supported growth; neither acetate nor fumarate were effective by themselves. In the absence of intermediates of the citric acid cycle, sodium bicarbonate or a combination of protogen + acetate allowed growth. With acetate present, protogen was replaceable by thiamine.

The B. stearothermophilus strain utilized glucose or sucrose; thiamine, biotin and nicotinic acid were required. A combination of arginine + histidine + isoleucine increased growth. The carbohydrate requirement appeared absolute.

The thermophilic $B$. circulans required glutamate or a combination of succinate + arginine +histidine; these sufficed for moderate growth. Supplementation with glycerol, sucrose, gluconate or glucose increased growth. Further addition of acetate decreased the lag phase. For the mesophilic B. circulans, either glucose or gluconate were suitable substrates; thiamine, biotin, riboflavin, and 'reduced sulphur' were required.

The advantages of thermophilic bacteria for studies of enzyme turnover are defined in recent reviews (Clegg \& Jacobs, 1953; Allen, 1953). Before testing the thermostability of enzymes in thermophilic bacteria, chemically-defined culture media suitable for mass cultures were needed to ensure good yields of organisms and enzymes, and reproducibility of enzymic activities. Such media were especially desirable for work with proteolytic enzymes whose activities are conspicuously dependent upon $\mathrm{Mn}, \mathrm{Mg}$, $\mathrm{Co}$, Ca or $\mathrm{Zn}$ ions (Smith, 1951; Crook, 1951). The concentration of these ions in natural materials varies widely.

Knight \& Proom (1950) noted that many strains of Bacillus circulans grew poorly in defined media suitable for strains of other species. One of our mesophils and one of our facultative thermophils belonged to the B. circulans group, and it was therefore of interest to extend the study of Knight \& Proom. The basal medium devised for this purpose appears suitable for mass cultures of our B. circulans strain and also for mesophilic and thermophilic variants 
belonging to several species and for a facultatively thermophilic strain of B. stearothermophilus - the species which includes the obligately thermophilic bacilli-since the technique devised for this purpose was simple, and the information so obtained was readily applicable to the mass cultivations needed for isolating enzymes in quantity. The definitions employed here for degrees of thermophily are those of Clegg \& Jacobs (1953).

\section{MATERIALS AND METHODS}

The culture methods were essentially those described elsewhere for aerabic protists (Hutner, 1950; Hutner, Provasoli \& Filfus, 1953). Experimental media in $5 \mathrm{ml}$. amounts were distributed in $25 \mathrm{ml}$. Pyrex Erlenmeyer flasks provided with glass or aluminium caps. In later work, to conserve space, media were distributed in $5 \mathrm{ml}$. amounts in $10 \mathrm{ml}$. borosilicate flasks having a broad base, thus resembling Fernbach flasks in shape; these flasks (Kimble Glass Company, Toledo, Ohio) allowed a greater surface : volume ratio (i.e. better oxygenation), and the flasks were less top-heavy. The flasks were incubated within chambers formed by inverting one Pyrex tray over another and sealing the joint with cellulose tape. Each chamber held up to thirty-eight $10 \mathrm{ml}$. flasks. Water was added to each tray to minimize the hazards of evaporation and uneven temperatures which are intensified at the incubation temperature for the thermophils. The temperatures of incubation, $37^{\circ}$ for the mesophils and $55^{\circ}$ for the thermophils, were read from thermometers kept in uninoculated flasks of culture medium; the difference between the air temperature in the incubator and that of the cultures was less than $0 \cdot 5^{\circ}$. Maximum growth for all cultures usually required 5-7 days.

All stock cultures were maintained on: Nutri-Peptone (Baltimore Biological Laboratory), 0.5 g.; beef extract (Difco), 0.5 g.; agar, 2.0 g.; distilled water to $100 \mathrm{ml}$; pH 6.5-7.0. Subcultures were made monthly and stored in the refrigerator after incubation. Bacteria scraped from agar slopes and suspended in the basal medium served as inocula. Growth was measured in optical density (O.D.) units as determined with a Welch Densichron. An o.D. of 1.0 equalled 0.50-0.55 g. dry-wt. washed bacteria/litre.

The basal medium shown in Table 2 , when supplemented with appropriate substrates and growth factors, allowed heavy growth of the organisms listed in Table 1 ; this medium could be made in double strength and refrigerated without precipitation.

The concentrations of metals listed in Table 2 refer to the metal content of the salts used; these were usually sulphates rather than the hygroscopic chlorides. Calcium was prepared as $\mathrm{CaCO}_{3}$ dissolved in $\mathrm{HCl}$. Molybdenum salts are poorly soluble in acid solutions and were not combined with other metals in one acidic stock solution. To avoid precipitation the molybdenum

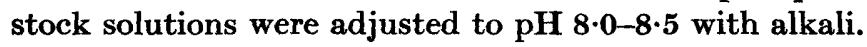

Transaconitic acid + triethanolamine served as buffers. Under the conditions of these experiments there was no evidence that this buffer pair had substrate activity. The pronounced alkalinization of the media (the $\mathrm{pH}$ 
may rise above $8 \cdot 5$ ) resulting from the consumption of organic acids and the liberation of ammonia from the amino-acids limited growth, making the use of concentrated buffer desirable.

Table 1. Species of Bacillus used Strain Mesophil

B. licheniformis, no. S8 (Ford strain)

B. circulans

Thermophil

B. licheniformis, no. S8

B. circulans, no. 7-2

B. stearothermophilus, no. B 1102

Source

I. M. Gunsalus

ATCC, no. 7046

Thermophilic variant of the Ford strain isolated by M. B. Allen Isolated from soil by M. B. Allen Originally from the Northern Regional Laboratory; sent through the courtesy of W. G. Walter.

Table 2. Basal medium

Ethylenediamine tetraacetic acid (EDTA)

$\mathrm{KH}_{\mathbf{2}} \mathrm{PO}_{4}$

$\mathrm{MgSO}_{4} \cdot 7 \mathrm{H}_{2} \mathrm{O}$

Mo (as ammonium molybdate)

'Metals 42'

$\begin{array}{ll} & \mathrm{NH}_{4} \mathrm{Cl} \\ 0.05 \mathrm{~g} . & \mathrm{Ca}(\text { as } \mathrm{Cl}) \\ 0.02 \mathrm{~g} . & \text { Transaconitic acid } \\ 0.05 \mathrm{~g} . & \text { Triethanolamine } \\ 0.001 \mathrm{~g} . & \text { Distilled water to } \\ 1.5 \mathrm{ml} . & \end{array}$

0.12 g. 0.001 g. $0.5 \mathrm{~g}$. $1.0 \mathrm{~g}$. $100 \mathrm{ml}$.

EDTA was used as the free acid purified by several recrystallizations from water; this preparation was a gift from the Bersworth Chemical Co., Framingham, Mass. The pH value of the medium was adjusted with $\mathrm{KOH}$ or $\mathrm{H}_{2} \mathrm{SO}_{4}$. The initial $\mathrm{pH}$ of the medium was 6.0-7.0 depending on the tolerance to the lower $\mathrm{pH}$ limit of the organism. One $\mathrm{ml}$. of 'Metals 42 ' contains (mg./ml.): EDTA, $2.5 ; \mathrm{Zn}, 4.0 ; \mathrm{Mn}, 3.0 ; \mathrm{Cu}, 0.25 ; \mathrm{Fe}, 0.1 ; \mathrm{B}$ (as $\left.\mathrm{H}_{3} \mathrm{BO}_{8}\right), 0.1$; Co, 0.04.

\section{RESULTS}

Bacillus circulans-mesophilic strain

Substrates. Initial pH 6.0. Glucose or gluconate $(0.5 \% ; \%$ means $\% \mathrm{w} / \mathrm{v}$, throughout unless otherwise indicated) were equally effective as substrates. Gluconate offered the advantage of being obtainable in pure form from the $\delta$-gluconolactone. The excess of chelating metals in the basal medium helped to compensate for the metal-binding effect of gluconate; the effectiveness of gluconate had been overlooked in previous experiments because of the metal deficiencies induced by its chelating ability.

Growth factors. Thiamine $\mathrm{HCl}(0.2 \mathrm{mg} . / 100 \mathrm{ml})$, biotin $(0.5 \mu \mathrm{g} . / 100 \mathrm{ml}$.$) and$ riboflavin (5.0 $\mu \mathrm{g}$. $/ 100 \mathrm{ml}$.) appear to be absolute requirements. 'Reduced sulphur', i.e. compounds more reduced than sulphates on the biosynthetic pathway to cystine and methionine, is also an absolute requirement (Table 3).

Stimulatory factors. In the presence of either glucose or gluconate and the other required nutrients, acetate $(0.04 \% \mathrm{Na}$ acetate trihydrate) was stimulatory. Cyanocobalamin (vitamin $\mathrm{B}_{12}$ ) was slightly stimulatory in the presence of L-cystine $(4.0 \mathrm{mg} . / 100 \mathrm{ml}$.). This stimulation was also evident when the cystine was replaced by thiosulphate; DL-methionine $(3.0 \mathrm{mg} . / 100 \mathrm{ml}$.) as the sole source of reduced sulphur yielded the same amount of growth as that 
permitted by cyanocobalamin plus either cystine or thiosulphate. It increased the density of growth from about 0.75 to 0.95 . Table 3 combines several experiments indicating the need for reduced sulphur carried out under similar conditions.

Table 3. Reduced sulphur requirement for Bacillus circulans mesophil in gluconate medium

\begin{tabular}{|c|c|c|c|c|c|}
\hline & $\begin{array}{l}\text { Sulphur } \\
\text { com- } \\
\text { pounds } \\
\text { (mg./ } \\
100 \mathrm{ml} \text { ) }\end{array}$ & $\begin{array}{l}\text { Optical } \\
\text { density }\end{array}$ & & $\begin{array}{l}\text { Sulphur } \\
\text { com- } \\
\text { pounds } \\
\text { (mg./ } \\
100 \mathrm{ml} \text {.) }\end{array}$ & $\begin{array}{l}\text { Optical } \\
\text { density }\end{array}$ \\
\hline $\begin{array}{l}\text { None } \\
\text { L-Cystine }\end{array}$ & $\begin{array}{r}0 \\
1.0 \\
4.0\end{array}$ & $\begin{array}{c}0 \\
0 \cdot 44 \\
0 \cdot 66\end{array}$ & DL-Homocystine & $\begin{array}{l}1.0 \\
4.0 \\
8.0\end{array}$ & $\begin{array}{l}0 \cdot 28 \\
0 \cdot 56 \\
0 \cdot 72\end{array}$ \\
\hline DL-Methionine & $\begin{array}{r}\mathbf{8 . 0} \\
\mathbf{3 . 0} \\
5 \cdot 0\end{array}$ & $\begin{array}{l}0.78 \\
0.36 \\
0.56\end{array}$ & Glutathione & $\begin{array}{r}5 \cdot 0 \\
10 \cdot 0 \\
50 \cdot 0\end{array}$ & $\begin{array}{l}0 \cdot 11 \\
0 \cdot 32 \\
0 \cdot 58\end{array}$ \\
\hline $\begin{array}{l}\text { L-Cysteine hydro- } \\
\text { chloride. } \mathbf{H}_{\mathbf{2}} \mathbf{O}\end{array}$ & $\begin{array}{l}1 \cdot 0 \\
4 \cdot 0\end{array}$ & $\begin{array}{l}0.62 \\
0.52 \\
0.7\end{array}$ & $\mathrm{Na}_{2}$ thiosulphate $5 \mathrm{H}_{2} \mathrm{O}$ & $\begin{array}{r}10 \cdot 0 \\
50 \cdot 0 \\
100 \cdot 0\end{array}$ & $\begin{array}{l}0 \cdot 38 \\
0 \cdot 52 \\
0 \cdot 78\end{array}$ \\
\hline Methionine sulphoxide & $\begin{array}{r}\mathbf{3 \cdot 0} \\
5 \cdot 0 \\
10 \cdot 0\end{array}$ & $\begin{array}{c}0.82 \\
0.22 \\
0.46 \\
0.56\end{array}$ & $\mathrm{Na}_{2} \mathrm{SO}_{4}$ (anhydrous) & $\begin{array}{r}10 \cdot 0 \\
50 \cdot 0 \\
100 \cdot 0\end{array}$ & $\begin{array}{l}\mathbf{0} \\
\mathbf{0} \\
\mathbf{0}\end{array}$ \\
\hline
\end{tabular}

Citric acid cycle components (DL-malate, fumarate, succinate, citrate) tested through a wide concentration range (0.01-0.5), and related compounds (L-glutamate, DL-alanine, and DL-aspartate) neither supported growth in the absence of glucose or gluconate nor were they stimulatory in the presence of glucose or gluconate.

\section{Bacillus circulans-thermophilic strain}

Substrates. Initial pH 6.0. Glucose, sucrose, gluconate, or glycerol in concentrations of $1.0 \%$, in combination with $(a)$ L-glutamate $(0.5 \%)$, or $(b)$ succinate $(0.3 \%)+$-arginine hydrochloride $(0.05 \%)+$ histidine hydrochloride $(0.02 \%)$ supported dense growth (o.D. 1.7). Glutamate or the succinate + arginine + histidine combination supported moderate growth (o.D. 0.7). The addition of acetate $(0.04 \% \mathrm{Na}$ acetate trihydrate) to these media decreased the lag time. The requirement for glutamate or for succinate + arginine + histidine is absolute.

\section{Bacillus licheniformis-mesophilic strain}

Substrates. Initial pH 6.5. Glycerol (1.0\%) or glucose (1.0\%). Sucrose or gluconate did not support growth.

Growth factors. The following amino-acids represent absolute requirements : DL-alanine (0.05\%), DL-aspartate (0.05\%), L-glutamate (0.5\%), glycine (0.05\%) L-arginine hydrochloride $(0.05 \%)$, L-histidine hydrochloride $(0.02 \%)$, and DL-lysine hydrochloride (0.05\%). 
Stimulatory factors. The addition of cytidylic acid or guanylic acid (up to $0.01 \%$ ) increased growth from 0.D. 0.45 to 0.9 ; the corresponding nucleosides and free purine and pyrimidine bases were inactive. Alkali-hydrolysed yeast nucleic acid was stimulatory to the expected extent. The nucleic acid was hydrolysed by suspending yeast nucleic acid in water, bringing the preparation to $\mathrm{pH} 9 \cdot 5$, autoclaving for $5 \mathrm{~min}$. at $115-120^{\circ}$, then neutralizing.

This organism grew in flakes; the others grew diffusely.

\section{Bacillus licheniformis-thermophilic strain}

Substrates. Initial pH 6.5. Glycerol (0.5\%), glucose ( $0.5 \%)$ or gluconate $(0.05 \%)$ allowed growth in the presence of glutamate or succinate. Glucose or gluconate was not as effective as glycerol. A combination of L-arginine hydrochloride $(0.05 \%)+\mathrm{L}$-histidine hydrochloride $(0.02 \%)+\mathrm{L}$-proline $(0.005 \%)$ also supported growth in the glycerol medium. It was advantageous to add $1.0 \mathrm{mg} . / 100 \mathrm{ml}$. additional $\mathrm{Mn}$ for this strain.

The utilization of intermediates of the citric acid cycle in glycerol media was surveyed. DL-Malate (up to 0.1\%) supported growth. Citrate (as tripotassium citrate monohydrate, $0.05 \%$ ) plus either $\mathrm{Na}$ acetate trihydrate $(0.01 \%)$ or $\mathrm{Na}$ fumarate (0.1\%) also supported growth. Acetate or fumarate alone, tested up to the toxic limit, did not support growth. Potassium citrate monohydrate was not employed in concentrations above $0.05 \%$ because of the induction of metal deficiencies through its chelating ability.

Sodium bicarbonate added aseptically to the glycerol medium in the absence of citric acid cycle intermediates allowed dense growth (o.D. up to 1.2). When the $\mathbf{p H}$ of the medium was raised to $\mathbf{7 \cdot 0}$, protogen (supplied as DL-thioctic acid, 6 : 8-dithiooctanoic acid, for which we are indebted to Dr E. L. R. Stokstad of the Lederle Laboratories Division of the American Cyanamid Company, Pearl River, N.Y.) at $40 \mathrm{~m} \mu \mathrm{g} . / 100 \mathrm{ml}$. supported growth in the presence of $0.03 \% \mathrm{Na}$ acetate trihydrate; higher concentrations of acetate were toxic. Thiamine hydrochloride $(0.1 \mathrm{mg} . / 100 \mathrm{ml}$.) replaced thioctic acid in the presence of acetate under these conditions.

\section{Bacillus stearothermophilus-facultative thermophilic strain}

Substrates. Initial pH 6.0. Glucose (1.0\%) or sucrose (1.0\%). The addition of $0.04 \%$ acetate as $\mathrm{Na}$ acetate trihydrate was stimulatory.

Growth factors. Thiamine hydrochloride $(15 \mu \mathrm{g} . / 100 \mathrm{ml}$.$) , biotin (0.9 \mu \mathrm{g} . / 100$ ml.), and nicotinic acid $(0 \cdot 15 \mathrm{mg} . / 100 \mathrm{ml}$.$) represent absolute requirements.$

Stimulatory factors. The addition to the glucose medium of a combination L-arginine hydrochloride $(0.01 \%)+\mathrm{L}$-histidine hydrochloride $(0.0045 \%)+$ DL-isoleucine (0.04\%) doubled growth (final o.D. 1·0).

\section{DISCUSSION}

Most recent attempts to explain thermophily ascribe such growth to an exceptionally rapid synthesis of enzymes which outstrips the thermally accelerated destruction of enzymes. That is to say, thermophily is viewed as 
an active process and not solely as a result of the possession of thermostable key enzymes (Allen, 1953; Clegg \& Jacobs, 1953). This postulated rapidity of synthesis and destruction of cell substance enhances the need for culture media which allow the organism to carry out essential syntheses at the highest possible rates. Such nutritionally adequate media should also, by simple modification, lend themselves to the manipulation of inorganic and organic components. For instance, in studying proteolytic enzymes it might be desirable to measure their production and activity as a function of concentration of the divalent ions active as co-factors. The relatively inexpensive defined media devised appear to be adequate for mass cultures, despite their simplicity; supplementation with complex materials (yeast autolysate, liver extracts, peptones, etc.) seldom increased growth more than 0.2-0.4 O.D. units.

Since this investigation was a survey of growth requirements in so far as this knowledge was needed for mass cultures, neither analysis of the kinetics of any isolated metabolic reaction nor an exhaustive analysis of any of the various nutritional patterns encountered was attempted; at this stage final growth was the index of adequacy of culture media. It proved necessary to inspect cultures at frequent intervals to avoid missing peak growth because rapid autolysis was likely to follow the attainment of full growth (Allen, 1950). These visual inspections of growth gave the impression that growth under these conditions was more rapid in the media which permitted the denser final growths.

Oxygen supply probably most commonly limits growth of these cultures in complete media. At elevated temperatures oxygen consumption, as indicated in the reviews previously cited, is accelerated; concurrently the solubility of oxygen in water is diminished. The use of media in shallow layers was mandatory in the technique employed here.

The diversity of nutritional requirements encountered with aerobic sporeforming bacteria suggests that they are biochemically more heterogeneous than is suggested by their shared morphological features. Even within a single species, e.g. B. licheniformis, the heterogeneity is striking. The findings of Campbell \& Williams (1953) indicate that a comparable heterogeneity holds for the obligate thermophils. They showed that strains of $\boldsymbol{B}$. stearothermophilus exhibited a variety of growth requirements; in many strains, moreover, these requirements depended on the temperature. In most instances, as in 'temperature' mutants, cultures incubated at the higher temperatures had additional exogenous requirements; less frequently the opposite was true. Consequently, the 'absolute' requirements listed in the present paper may not hold for other than the stated temperatures. The nutrition of the aerobic spore-formers as outlined to date gives the impression of a sampling of a diversity of nutritional patterns.

The only novel phenomenon noted in the present work was with an aberrant agar-liquefying strain of $B$. stearothermophilus-a mutual sparing between riboflavin and calcium. Allen (unpublished) has found this phenomenon to be common among bacilli. The complexity of this calcium-riboflavin relation precludes a detailed treatment at this time. In any event, the media devised 
to date, on the basis of preliminary experiments with additional strains, appear to be generally suitable for mass cultures. Several strains of facultatively thermophilic B. stearothermophilus obtained from the National Canners Association, Washington, D.C., grew to o.D. 2.4 when the basal medium was supplemented with glucose, acetate, and the vitamins and amino-acids found necessary by Campbell \& Williams (1953). A thermophilic strain of B. coagulans, no. 139, obtained from Dr Allen, grew to 0.D. 2.8 in the basal medium supplemented with glutamate plus either glycerol or carbohydrate. A mesophilic B. sphaericus (no. RA91, obtained from Dr Allen) reached o.D. 2.2 in the basal medium supplemented with glucose, acetate, and amino-acids.

The nutritional patterns of the five strains discussed here may have their counterparts elsewhere in microbial nutrition. A requirement similar to that for 'reduced sulphur' in the $B$. circulans mesophil was described for certain mutants of Bacterium coli (Lampen, Roepke \& Jones, 1947), in Saprolegniaceae (Reischer, 1951), and in Proteus morganii (Meyers \& Porter, 1944), to list only non-parasitic bacteria; it has not hitherto been reported in bacilli. The growth stimulation of the $\boldsymbol{B}$. circulans mesophil by cyanocobalamin or methionine accords with evidence which implicates cyanocobalamin in methylations. This raises the question of whether the methionine requirements reported by Campbell \& Williams for several strains of $B$. stearothermophilus represent either $(a)$ a requirement for 'reduced sulphur', $(b)$ a specific requirement for methionine, or $(c)$ a deficiency in the synthesis of labile methyl groups. The 'glutamate' requirement for the $\boldsymbol{B}$. circulans and $\boldsymbol{B}$. licheniformis thermophils resembles the stimulation described by Wiame \& Storck (1953) for a mutant of $\boldsymbol{B}$. subtilis; glutamate here was replaceable, as with the $B$. licheniformis thermophil, by proline. The activity of succinate in replacing glutamate for the $B$. circulans thermophil suggests that the 'glutamate' requirement is essentially a requirement for a citric acid cycle component, and that permeability factors and restrictions in transamination underlie many of the differences among strains. To chart the interrelationships governing the utilization of carbohydrate, glycerol, acetate, citric acid cycle intermediates, and the requirements for thiamins, biotin, and pantothenate, is a task as yet attacked only in piecemeal fashion in metazoan and microbial nutrition. A glutamate requirement for a strain of $\boldsymbol{B}$. cereus was mentioned by Foster \& Heiligman (1949). The basis for the requirement for carbohydrate in B. stearothermophilus, unexpected in an aerobic organism, is obscure. The non-accumulation of acid suggests that this organism derives energy from oxidation as well as glycolysis. Hendlin (1949) described a strain of $B$. subtilis which required carbohydrates; citric acid cycle intermediates did not support growth.

The stimulation by nucleotides of the $B$. licheniformis mesophil and the inactivity of adenosine contrasts with the repeated observation that adenosine is required for spore germination in Bacillus (Pulvertaft \& Haynes, 1951; Stewart \& Halvorsen, 1953).

Interactions among protogen, thiamine, malate, acetate, and bicarbonate such as that detected in the thermophilic $B$. licheniformis may become familiar now that synthetic protogen is available in the form of pL-thioctic acid. 
A similar interaction was described by Lytle, Zulick \& O'Kane (1951) for Streptococcus faecalis; with gluconate as substrate, acetate was interchangeable with protogen; and malate, succinate, or bicarbonate were in turn interchangeable with protogen or acetate. Sparing of thiamine by protogen +acetate was described for a mutant of Bacterium coli (Reed \& DeBusk, 1952).

Non-metabolizable EDTA replaced the citrate formerly employed as metal buffer and allowed a clearer demonstration of the relations of substrate to other nutrients. As mentioned, transaconitic acid buffer was considered to be unattacked under the present cultural conditions, but there is the possibility that under certain circumstances it may be convertible to the metabolizable cis isomer. In future work it is hoped to replace the potentially metabolizable aconitic acid with buffers less likely to be physiologically active.

The studies at the Mount Sinai Hospital were assisted by a grant from the Office of Naval Research, and those at Haskins Laboratories by grants from the Lederle Laboratories Division of the American Cyanamid Co. and the Alfred L. Loomis Foundation.

\section{REFERENCES}

Aluen, M. B. (1950). The dynamic nature of thermophily. J. gen. Physiol. 33, 205. Allen, M. B. (1953). Bact. Rev. 17, 125.

Campbell, L. I. \& Williams, O. B. (1953). The effect of temperature on the nutritional requirements of facultative and obligate thermophilic bacteria. J. Bact. 65, 141.

ClegG, L. F. L. \& JACoBs, S. E. (1953). Environmental and other aspects of adaptation in thermophiles. Symp. Soc. gen. Microbiol. 3, Adaptation in microorganisms.

Crook, E. M. (1951). Specificity and mode of action of proteolytic enzymes. J. Soc. Leath. Tr. Chem. 35, 257.

Foster, J. W. \& Herugman, F. (1949). Biochemical factors influencing sporulation by a strain of Bacillus subtilis. J. Bact. 57, 639.

HendLIN, D. (1949). The nutritional requirements of a bacitracin-producing strain of Bacillus subtilis. Arch. Biochem. 24, 435.

Hutner, S. H. (1950). Anaerobic and aerobic growth of purple bacteria (Athiorhodaceae) in chemically-defined media. J. gen. Microbiol. 4, 286.

Hutner, S. H., Provasoli, L. \& Filfus, J. (1953). Nutrition of some phagotrophic fresh-water chrysomonads.' Ann. N.Y. Acad. Sci. 55, 852.

Knight, B. C. J. G. \& Proom, H. (1950). A comparative survey of the nutrition and physiology of mesophilic species in the genus Bacillus. J. gen. Microbiol. 4, 508.

LAmpen, J. O., Roepke, R. R. \& Jones, M. J. (1947). III. Mutant strains of Escherichia coli unable to utilize sulfate for their complete sulfur requirements. Arch. Biochem. 13, 55.

Lytle, V. L., ZuLrck, S. M. \& O'KANe, D. J. (1951). Replacement of the pyruvate oxidation factor by carbon dioxide. J. biol. Chem. 189, 551.

Meyers, F. P. \& Porter, J. R. (1944). The nutrition of Proteus morganii. Sulphur requirements. J. Bact. 47, 29.

Pulvertaft, R. J. V. \& Haynes, J. A. (1951). Adenosine and spore germination; phase-constrast studies. J. gen. Microbiol. 5, 657.

Reed, L. J. \& DeBusk, B. G. (1952). A conjugate of $\alpha$-lipoic acid required for oxidation of pyruvate and $\alpha$-ketoglutarate by an Escherichia coli mutant. J. biol. Chem. 199, 878. 
Rerscher, H. S. (1951). Growth of Saprolegniaceae in synthetic media. I. Inorganic nutrition. Mycologia, 43, 142.

Smith, E. L. (1951). Proteolytic enzymes. In The Enzymes. I, pt. 2, p. 793. Edited by Sumner, J. B. and Myrbäck, K., New York: Academic Press.

Stewart, B. T. \& Halvorsen, H. O. (1953). Studies on the spores of aerobic bacteria. I. The occurrence of alanine racemase. J. Bact. $65,160$.

WiAme, J. M. \& Storck, R. (1953). Métabolisme de l'acide glutamique chez Bacillus subtilis. Biochim. biophys. Acta, 10, 268.

(Received 12 June 1953) 